ORIGINAL PROF-2049

\title{
ACCURACY OF THE UPPER LIP BITE TEST;
}

Modified Mallampati classification in predicting difficult endotracheal intubation.

\author{
Dr. Muhammad Atif, Dr. Muhammad Abdullah, Dr. Muhammad Javad Yousaf, Dr. Khalid Buland
}

ABSTRACT... Objective: To compare the accuracy of Upper lip bite test with modified Mallampati classification for predicting the difficult laryngoscopic intubation. Study Design: Cross sectional Study. Place and duration of study: The study was carried out at Department of Anaesthesiology, Intensive Care and Pain management, Combined Military hospital, Rawalpindi from September 2008 to August 2009. Patients and Methods: Four hundred patients undergoing elective surgery meeting the inclusion/exclusion criteria were enrolled after written informed consent. The airways of the patients were evaluated by using the modified Mallampati classification (MMP) and the Upper lip bite test (ULBT). MMP class 3 or 4 and ULBT class 3 were considered as indicators of difficult intubation. The laryngeal view was graded by Cormack and Lehane classification (Gold standard). Grade 1 or 2 was considered to represent easy intubation and grade 3 or 4 to represent difficult intubation. Sensitivity, specificity, positive predictive value, negative predictive value and diagnostic accuracy were calculated for both the tests separately by using the $2 \times 2$ table. Results: ULBT had a higher accuracy of $94 \%$, specificity of $99.2 \%$ and positive predictive value $70 \%$ compared to MMP accuracy of $82.7 \%$, specificity of $84.4 \%$ and positive predictive value of $22.7 \%$. Conclusions: The diagnostic accuracy of the Upper lip bite test was more than the modified Mallampati classification. We suggest that it be compared with the other prevailing tests as well which are often used to assess difficult intubations.

Key words: Upper lip bite test, Modified Mallampati classification, Cormack \& Lehane grading, Difficult intubation.

Article Citation

$\checkmark \quad$ Atif M, Abdullah M, Yousaf MJ, Buland K. To compare the accuracy of the upper lip bite test with modified Mallampati classification in predicting difficult endotracheal intubation. Professional Med J Feb 2013;20(1):132-138.

\section{INTRODUCTION}

Maintenance of airway is always the primary concern for the anaesthetist. Endotracheal intubation is usually carried out for the maintenance of general anaesthesia. Failed tracheal intubation has been identified as one of the anaesthesia related causes of death or permanent brain damage. Unexpected difficulty, as during a failed intubation, might subject the intubator to stress; his or her performance including decision-making might be sub optimal under stressful conditions. The impact of multiple attempts at intubation resulting in laryngeal trauma and excessive autonomic stimulation can be anything but beneficial to the patient. If a difficult intubation is identified in advance a senior anaesthetist and specialized tracheal intubation techniques may be present to deal with such a situation.

S. Rao Mallampati described an airway classification in 1985 to assess difficulty in intubation, preoperatively, based on the clinical assessment of the pharynx ${ }^{1}$.

Khan ZH introduced the Upper Lip bite test in 2003. The upper lip bite test, a reasonably easy test, evaluates the patient's ability to reach or completely cover the upper lip with lower incisors. Since the range and freedom of mandibular movement and the architecture of the teeth have pivotal roles in facilitating laryngoscopic intubation, the upper lip bite test could serve as a good predictor for difficult laryngoscopic intubation ${ }^{2}$.

Studies are being carried out in different countries to test the validity of upper lip bite test and its comparison with rest of routinely used clinical tests ${ }^{3,4,5}$. Locally Studies have been conducted over different clinical tests to predict difficult intubation $n^{6,7}$ but studies over upper lip bite test have not been conducted as much as at international level.

To test the accuracy of upper lip bite test and its comparison with commonly used modified Mallampati 
classification in local population we conducted a study in patients undergoing general anaesthesia.

\section{PATIENTS AND METHODS}

This cross sectional study was carried out at Anaesthesia department, Combined Military Hospital Rawalpindi, from September 2008 to August 2009 after approval of the "hospital ethics committee". A total of 400 patients fulfilling the inclusion/exclusion criteria were included in the study. Non probability convenient sampling was done for patients scheduled to undergo surgery under general anaesthesia.

Patients of age more than 16 years undergoing a broad variety of elective surgical procedures requiring (nonrapid sequence induction) endotracheal intubation were included in the study. Patients unable to open mouth, with laryngeal, pharyngeal masses, other tumors of oral cavity, those with limitation of cervical movements and edentulous patients were excluded from the study. Pre-anaesthesia assessment of patients undergoing elective surgery was done a night before surgery. The patients were briefed about the study being carried out and a written informed consent was taken both for the study as well as, for the general anaesthesia.

The airways of the patients were evaluated by using the modified Mallampati classification and the Upper lip bite test. The examination to determine the Mallampati classification was done with the aid of a flashlight. The patients were in sitting position at the level of observer with the tongue fully protruding; they were not asked to say 'an'. Upper lip bite test was assessed with patient sitting, head in neutral position. The patient was asked to completely cover the upper lip with the lower incisors. Ability of the patient to bite his / her upper lip was assessed and graded by the investigator after a proper demonstration of the test to the patient. Mallampati class 3 or 4 and Upper lip bite class 3 were considered as indicators of difficult intubation (Figure 1).

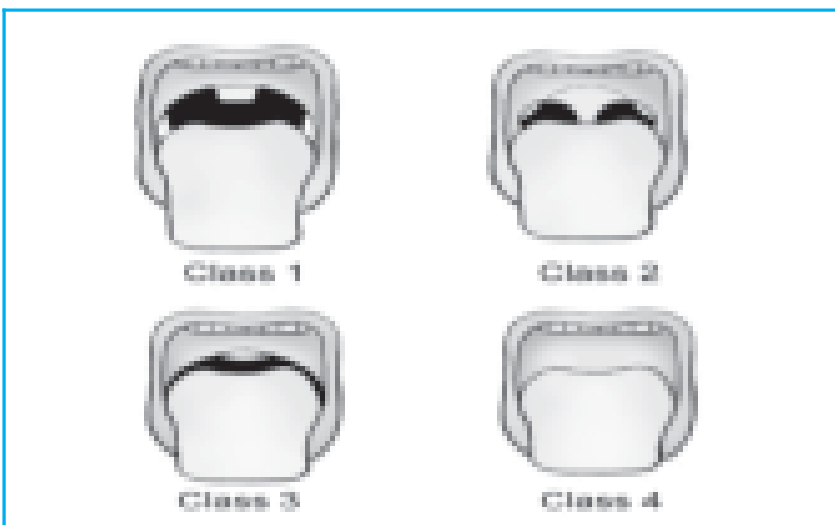

Fig-1. Modified Mallampati classification

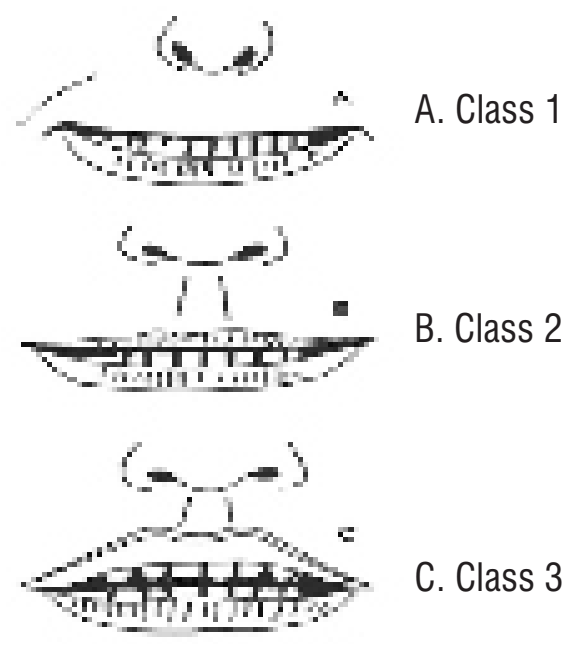

Upper Lip bite test

Grade 1 Grade 2 Grade 3 Grade 4

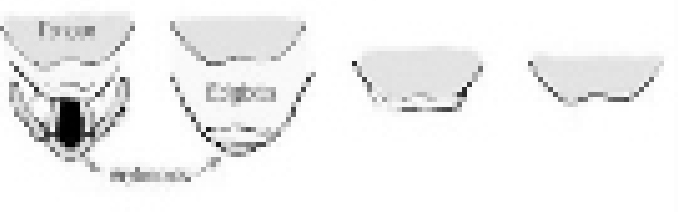

Cormack and lehane classification

In the operation theatre general anaesthesia was induced according to our standard operating procedures using Propofol $(2 \mathrm{mg} / \mathrm{kg})$, Morphine $(0.1 \mathrm{mg} / \mathrm{kg})$ and Atracurium $(0.5 \mathrm{mg} / \mathrm{kg})$ followed by mask ventilation with a mixture of Nitrous Oxide, Oxygen and Isoflurane. The head was placed in the 
sniffing position and laryngoscopy was performed with Macintosh blade without extra laryngeal pressure. The intubation was done using an appropriate sized laryngoscope blade. The laryngeal view was graded according to the method described by Cormack and Lehane which was taken as Gold standard. Grade 1 or 2 was considered to represent easy intubation and grade 3 or 4 to represent difficult intubation (Figure 1). To remove any doubt of confounding variable of inexperience, an anaesthesiologist with minimum 4 years of clinical experience performed the laryngoscopy and intubation. The bias was avoided by keeping the intubating anaesthesiologist blind of patient's pre-operative modified Mallampati and upper lip bite test score. The Performa was filled out by a person not involved in induction / intubation of patient. The preoperative assessment data and the intubation findings were used to determine the accuracy of both the tests in predicting difficult intubation.

\section{Data Analysis}

All the data was entered in the computer using Statistical Package for Social Sciences (SPSS) version 17.0. In addition to patient's age and sex, preoperative modified Mallampati score, Upper lip bite test score and Cormack-Lehane classification were the variables recorded. Mean and Standard deviation were measured for age. Frequency and Percentage was calculated for sex, modified Mallampati score, Upper lip bite test score and Cormack-Lehane classification.
Sensitivity, specificity, positive predictive value, negative predictive value and diagnostic accuracy were calculated for both the tests separately by using the $2 \times 2$ table.

\section{RESULTS}

The age group of patients in the study was 16 to 63 . Mean age was $37.2 \pm 10.8$. Mean age for males and females separately was $37.8 \pm 10.9$ and $36.7 \pm 10.7$ respectively. Females comprised $228(57 \%)$ of the study population where as 172 (43\%) were males.

75 patients (18.75\%) were predicted to have difficult intubation by modified Mallampati classification. 10 patients $(2.5 \%)$ were predicted to have difficult intubation by Upper lip bite test. There were 28 (7\%) cases of difficult intubation, taking Cormack and Lehane grading of laryngoscopic view as the gold standard. Relationship between the predictive tests and grading of laryngoscopy are shown in Table I. The positive predictive value, negative predictive value, sensitivity, specificity and diagnostic accuracy for both the tests are compared in Figure 2.

It was observed that the ULBT had more specificity, positive predictive value and accuracy than the MMP in predicting difficult intubation (Figure 2). However the sensitivity and negative predictive value of MMP was more than the ULBT (Figure 2).

\begin{tabular}{|c|c|c|c|c|c|c|c|}
\hline \multirow[t]{2}{*}{ MMP } & \multicolumn{2}{|c|}{ Cormack \& Lehane's } & \multirow[t]{2}{*}{ Total } & \multirow[t]{2}{*}{ ULBT } & \multicolumn{2}{|c|}{ Cormack \& Lehane’s } & \multirow[t]{2}{*}{ Total } \\
\hline & $\begin{array}{c}\text { Easy / Grade } \\
1 \& 2\end{array}$ & $\begin{array}{c}\text { Difficult } \\
\text { Grade } 3 \& 4\end{array}$ & & & $\begin{array}{l}\text { Easy / Grade } \\
1 \& 2\end{array}$ & $\begin{array}{c}\text { Difficult } \\
\text { Grade } 3 \& 4\end{array}$ & \\
\hline $\begin{array}{l}\text { Predicted Easy / } \\
\text { Class } 1 \& 2\end{array}$ & $\begin{array}{l}\text { True negative } \\
\qquad 314\end{array}$ & $\begin{array}{c}\text { False negative } \\
11\end{array}$ & 325 & $\begin{array}{l}\text { Predicted Easy / } \\
\text { Class } 1 \& 2\end{array}$ & $\begin{array}{l}\text { True negative } \\
\quad 369\end{array}$ & $\begin{array}{l}\text { False negative } \\
\qquad 21\end{array}$ & 390 \\
\hline $\begin{array}{l}\text { Predicted Difficult / } \\
\text { Class } 3 \& 4\end{array}$ & $\begin{array}{l}\text { False positive } \\
\quad 58\end{array}$ & $\begin{array}{l}\text { True positive } \\
17\end{array}$ & 75 & $\begin{array}{c}\text { Predicted } \\
\text { Difficult / } \\
\text { Class } 3\end{array}$ & $\begin{array}{c}\text { False positive } \\
3\end{array}$ & $\begin{array}{l}\text { True positive } \\
7\end{array}$ & 10 \\
\hline Total & 372 & 28 & 400 & Total & 372 & 28 & 400 \\
\hline
\end{tabular}

Table-I. Modified mallampati classification(mmp) \& upper lip bite test(ulbt) versus cormack \& lehane's grades 


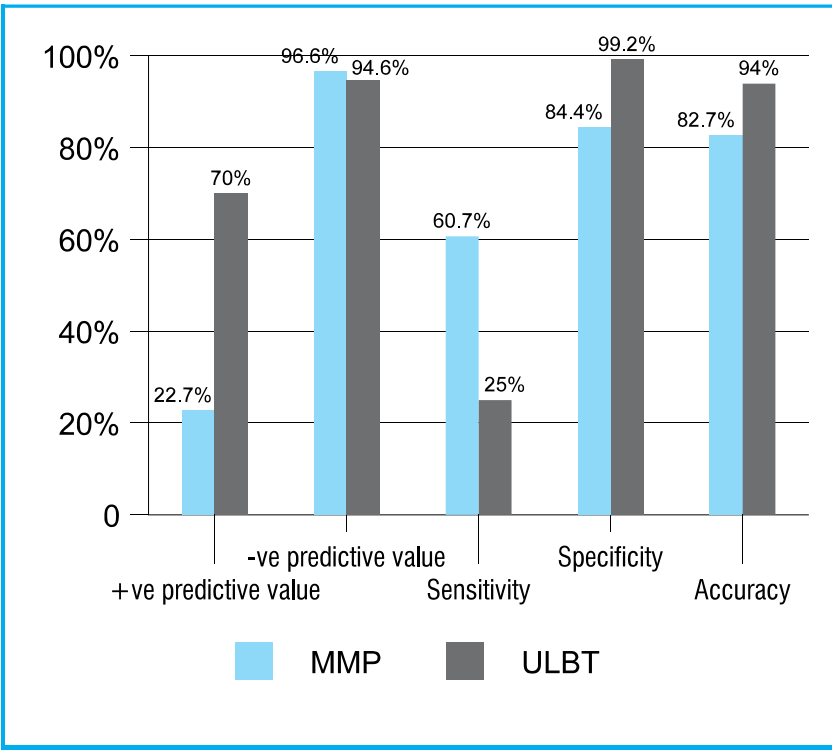

Fig-2. Comparison of modified mallampati classification (MMP) and upper lip bite test (ULBT)

\section{DISCUSSION}

The incidence of difficult intubation by rigid laryngoscopy varies from $0.5-13.6 \%$ in published studies $^{8,9,10}$. If those patients in whom intubation proves difficult could be identified in advance, it could be arranged that a senior anaesthetist, properly equipped to deal with the problem, could be present ${ }^{11,12}$.

Modified Mallampati classification has been in use for more than 2 decades and over the years many of its limitations have been pointed out by various trials. The absence of a definite demarcation between class2 \& class 3 and between class 3 \& class 4 group and effect of phonation on the oropharyngeal classification lead to high inter observer variability and decreased reliability $^{13,14,15,16}$.

The search for predictive tests that has ease of applicability, reliability and accuracy continues. Upper Lip Bite Test was such an attempt. The Combination of jaw subluxation and buck teeth was used as an alternative to the widely used test the modified Mallampati Test. ULBT is easy to perform within seconds by demonstrating it to the patient.
The incidence of difficult intubation in our trial was 7\%. The relatively high incidence of difficult intubation in our study maybe due to the fact that the application of extralaryngeal pressure during intubation was considered as a difficult intubation. This may also be due to special anthropomorphic features of our patients.

In our study we found the sensitivity and specificity of modified Mallampati Classification was $60.7 \%$ and $84.4 \%$ respectively. The sensitivity of ULBT was $25 \%$ which is comparable to that of Eberhart et $\mathrm{al}^{17}$ study which had a sensitivity of $28.2 \%$. Similarly study done by Chohedri et $\mathrm{al}^{18}$ had a sensitivity of $14.2 \%$. The original study by Khan et $\mathrm{al}^{2}$ had a sensitivity of $76.5 \%$. Hester et al ${ }^{19}$ trial had a sensitivity of $55 \%$. We were unable to replicate the high sensitivity of the original study, the cause of which may be the low incidence of ULBT 3 class in our study. The specificity of ULBT was $99.2 \%$ in our study and much higher compared to Eberhart et al (92.5\%) and Khan et al (88.7\%) trials. But the specificity of our study was comparable to specificity of Chohedri et al study (98.3\%) and Hester et al study (97\%).

The positive predictive value of modified Mallampati classification $(22.7 \%)$ in our study is less than that for ULBT (70\%) and almost similar to that of Eberhart et al trial $(19.5 \%)$ but higher than that found by Khan et al (13\%). The positive predictive value of ULBT is higher in our study (70\%) as compared to Eberhart et al trial $(33.6 \%)$ and Khan et al trial (28.9\%). This may be because of low number of ULBT class 3 cases in our study.

The negative predictive value was more than $90 \%$ in our study for both the tests individually (96.6\% - MMP, $94.6 \%$ - ULBT) thus stressing upon the fact that all these tests can be good predictors of easy intubation rather than as positive predictors of difficult intubation which has a very low incidence. This was one of the conclusions made by Eberhart et al and Hester et al. 
In original study by Khan et al the accuracy of ULBT was $88 \%$ compared to accuracy of modified Mallampati classification which was $67.7 \%$. This was almost replicated in the trial by Eberhart et al, $84.9 \%$ for ULBT and $62.1 \%$ for modified Mallampati classification. Hester et al study revealed accuracy of $90 \%$ for ULBT and $64 \%$ for MMP. However Chohedri et al study had results with accuracy of ULBT as $96 \%$ and MMP as $93.8 \%$. In our study the ULBT had higher accuracy of $94 \%$ compared to that of MMP $82.7 \%$.

Thus in our study we found that sensitivity of ULBT (25\%) was much low compared to modified Mallampati classification (60.7\%). However ULBT had a higher accuracy of $94 \%$, specificity of $99.2 \%$ and positive predictive value $70 \%$ compared to modified Mallampati classification accuracy of $82.7 \%$, specificity of $84.4 \%$ and positive predictive value of $22.7 \%$.

Therefore ULBT has shown so far to have some very promising and encouraging results as a bed side test in various studies. ULBT has also been used to predict the difficult mask ventilation with promising results ${ }^{20}$. Similarly ULBT has also been used as a predictor of difficult intubation with the Videolaryngoscope (GlideScope) $^{21}$. In a case report by Khan et al ULBT had predicted easy intubation in a patient suffering from both Cushing's and Nelson's syndromes, which had been predicted difficult by MMP22.

However upper lip bite test like modified Mallampati classification has certain limitations like its inability to assess edentulous patients. ULBT just like the MMP does not assess the neck mobility and may not be a good predictor of difficult intubation in patients with goitre, laryngeal, pharyngeal masses and other tumors of oral cavity. In short the predication of difficult intubation becomes more accurate when multiple clinical tests are used. The routinely used tests like Sternomental distance, thyromental distance, inter incisor gap and Wilson risk scores should be used along with the upper lip bite test and modified Mallampati classification for airway assessment.

\section{CONCLUSIONS}

In conclusion, the ULBT has high level of accuracy and specificity compared to MMP. It could easily predict $99.2 \%$ of easy intubations. It has the inherent quality to unveil and unravel the hidden airway anatomy and the potential laryngoscopic difficulties while the mouth remains closed. Therefore, we conclude that ULBT is an acceptable option for predicting difficult intubation. However the high negative predictive values of both the tests indicate that they are good predictors of possible easy intubation rather than difficult intubation.

In this study, we compared ULBT with the MMT but suggest that it be compared with the other prevailing tests as well which are often used to assess difficult intubations.

\section{Copyright $\subseteq 25$ Aug, 2012.}

\section{REFERENCES}

1. Mallampati SR, Gatt SP, Gugino LD, Desai SP, Waraksa $B$, Freiberger D et al. A Clinical Sign to predict difficult tracheal intubation: A prospective study. Can Anesth Soc J 1985; 32: 429-34.

2. Khan ZH, Kashfi A, Ebrahimkhani E. A comparison of the upper lip bite test (a simple new technique) with modified Mallampati classification in predicting difficulty in endotracheal intubation: a prospective blinded study. Anesth Analg 2003; 96: 595-9.

3. Khan ZH, Mohammad M. A comparison of the Upper Lip bite test with Sternomental, Thyromental and Inter-incisor distances in predicting difficulty in intubation. Can J Anaesth 2006; 53 :26404.

4. Khan ZH, Mohammadi M, Rasouli MR, Farrokhnia F $\mathrm{Khan} \mathrm{RH}$. The diagnostic value of the upper lip bite test combined with sternomental distance, thyromental distance, and interincisor distance for prediction of easy laryngoscopy and intubation: a prospective study. Anesth Analg $2009 ; 109: 822-4$. 
5. Salimi A, Farzanegan B, Rastegarpour A, Kolahi AA. Comparison of the upper lip bite test with measurement of thyromental distance for prediction of difficult intubations. Acta Anaesthesiol Taiwan 2008 ;46:61-5.

6. Siddiqi R, Kazi WA. Predicting difficult intubation - a comparison between Mallampati classification and Wilson Risk-Sum. J Coll Physicians Surg Pak 2005;15:253-6.

7. Khan RA, Hussain T. Value of predictive tests in evaluating the diffcult airway. Pak Armed Forces Med J 2002; 52: 9-11.

8. Savva D. Prediction of difficult tracheal intubation. $\mathrm{Br}$ J Anaesth 1994;73:149-53.

9. Wilson ME, Spiegelhalter D, Robertson JA, Lesser P. Predicting difficult intubation. $\mathrm{Br} J$ Anaesth 1988;61:211-6.

10. Yildiz TS, Korkmaz F, Solak M, Toker K, Erciyes N, Bayrak $F$ et al. Prediction of difficult tracheal intubation in Turkish patients: a multi-center methodological study. Eur J Anaesthesiol 2007;24:1034-40.

11. Practice guidelines for management of the difficult airway: an updated report by the American Society of Anesthesiologists Task Force on management of the difficult Airway. Anesthesiology 2003;98:1269-77.

12. Rosenblatt WH. The airway approach algorithm: a decision tree for organizing preoperative airway information. J Clin Anesth 2004;16:312-16.

13. Iohom G, Ronayne M, Cunningham AJ. Prediction of difficult tracheal intubation. $J$ Anaesthesiol 2003;20:31-6.

14. Lee A, Fan LT, Gin T, Karmakar MK, NganKee WD. A systematic review (meta-analysis) of the accuracy of the Mallampati tests to predict the difficult airway. Anesth Analg 2006;102:1867-78.
15. Rosenstock C, Gillesberg I, Gatke MR, Levin D, Kristensen MS, Rasmussen LS. Inter-observer agreement of tests used for prediction of difficult laryngoscopy/tracheal intubation. Acta Anaesthesiol Scand 2005;49:1057-62.

16. Shiga T, Wajima Z, Inoue T,Sakamoto A. Predicting difficult intubation in apparently normal patients: a meta-analysis of bedside screening test performance. Anesthesiology 2005;103:429-37.

17. Eberhart LH, Arndt C, Cierpka T, Schwanekamp J, Wulf $\mathrm{H}$, Putzke $\mathrm{C}$. The reliability and validity of the Upper lip bite test compared with the Mallampati classification to predict difficult laryngoscopy:an external prospective evaluation. Anesth Analg 2005;101: 284 9.

18. Chohedri AH, Allahyari E, Tabari M. The upper lip bite test, prediction of difficult endotracheal intubation. Professional Med J 2005; 12: 440-5.

19. Hester CE, Dietrich SA, White SW, Secrest JA, Lindgren $\mathrm{KR}$, Smith T. A comparison of preoperative airway assessment techniques: the modified Mallampati and the upper lip bite test. AANA J 2007; 75: 177-82.

20. Khan ZH, Mofrad MK, Arbabi S, Javid MJ, Makarem J Upper lip bite test as a predictor of difficult mask ventilation: a prospective study. Middle East $\mathrm{J}$ Anesthesiol 2009;20:377-82.

21. Tremblay MH, Williams S, Robitaille A, Drolet P. Poor visualization during direct laryngoscopy and high upper lip bite test score are predictors of difficult intubation with the GlideScope videolaryngoscope. Anesth Analg 2008 May;106:1495-500.

22. Khan ZH, Gharabaghian $M$, Nilli $F$, Ghiamat $M$, Mohammadi M. Easy endotracheal intubation of a patient suffering from both Cushing's and Nelson's syndromes predicted by the upper lip bite test despite a Mallampati Class 4 airway. Anesth Analg. 2007;105:786-7. 


\section{AUTHOR(S):}

1. DR. MUHAMMAD ATIF

( MBBS, FCPS, Anaesthetist)

$144 \mathrm{Med} B \mathrm{n}$

2. DR. MUHAMMAD ABDULLAH

MBBS, FCPS, Anaesthetist

$\mathrm{CMH}$, Gilgit

3. DR. MUHAMMAD JAVAD YOUSAF, MBBS

Army Medical College, Rawalpindi

4. Dr. Khalid Buland

MBBS, FCPS, Anaesthetist

$\mathrm{CMH}$, Lahore

\section{Correspondence Address:}

Dr. Muhammad Abdullah

House 138/1 Sector B2 College Road

Township Lahore

drabdullah1979@gmail.com

\section{PREVIOUS RELATED STUDIES}

Abdul Hameed Chohedri, Elahe Allahyari, Masoomeh Tabari. THE UPPER LIP BITE TEST; PREDICTION OF DIFFICULT ENDOTRACHEAL INTUBATION (Original)Prof Med Jour 12(4) 440-445 Oct, Nov, Dec 2005.

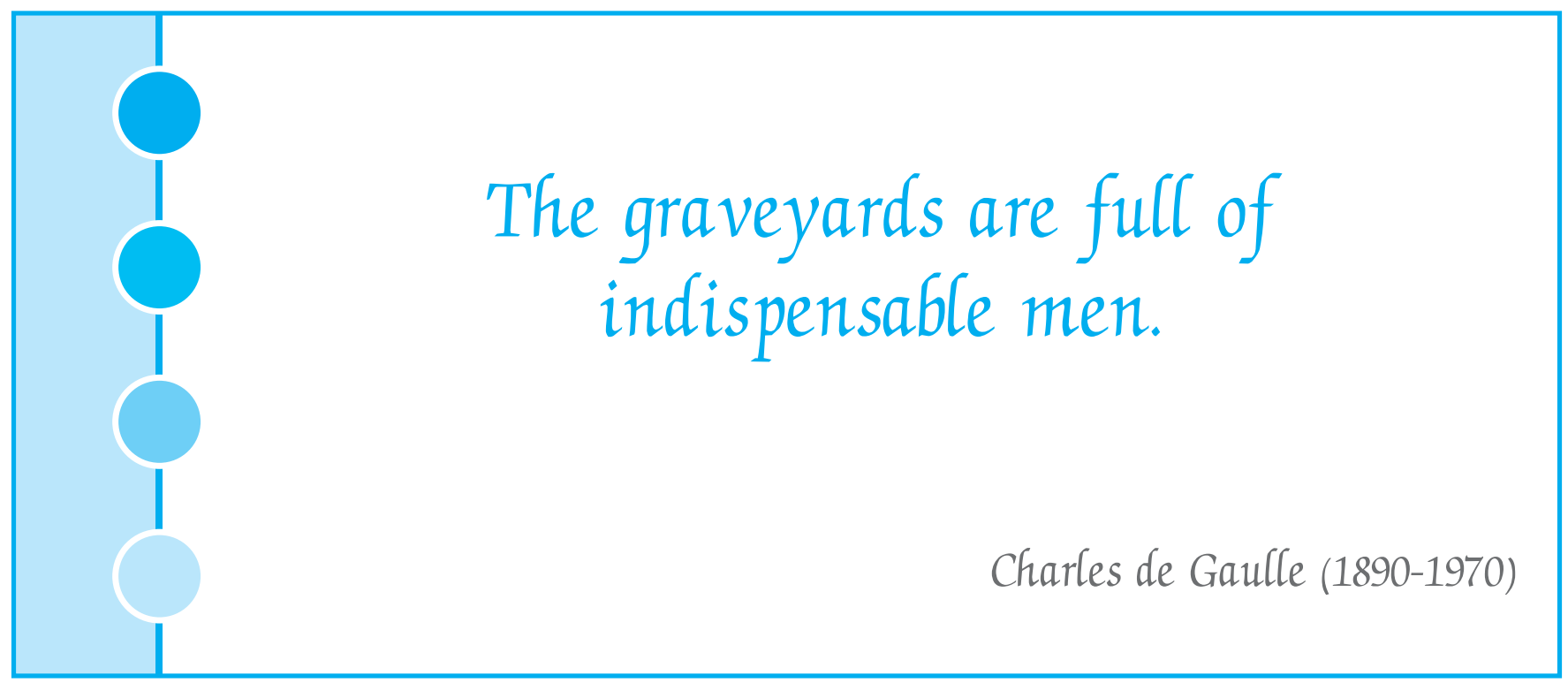

